June - 2009

\title{
Cognitive, Instructional, and Social Presence as Factors in Learners' Negotiation of Planned Absences from Online Study
}

\author{
Dianne Conrad \\ Athabasca University, Canada
}

\begin{abstract}
Adult learners value the flexibility and convenience offered to them as online learners, and many learners are required to absent themselves from their online classes during courses in order to accommodate demanding schedules. What factors and tensions contribute to learners' decisionmaking at these times? This qualitative study considered the planned absences of learners engaged in an online graduate course at a large university. Working within the framework provided by cognitive, instructional, and social presences, findings showed the following: (1) learners understood and accommodated the relationship and importance of the affective domain to their cognitive successes in learning, (2) successful learners demonstrated insightful selfknowledge in using meta-cognitive strategies, and (3) learners' external support systems were fundamental to their ability to continue to learn when absences occurred. The study's findings corroborate other recent research that similarly stresses the complexity and interrelated nature of the adult learning process.
\end{abstract}

Keywords: Online learning; pedagogy; social presence; cognitive presence

\section{Introduction}

In our 21 st century technology-enhanced lives, the advanced state of technological access that we enjoy presents a mixed blessing. It is true that we can establish near-instant contact with anyone or any type of information anywhere in the world. At the same time, however, we are overwhelmed with connectivity. We struggle to establish new boundaries that will bring balance to our lives by permitting us to escape the omnipresence of technology and its many devices.

Online learning presents a similar dichotomy. Touted as making learning more accessible and more flexible, it does indeed provide learners with countless and never-ending opportunities to access courses, programs, and educational credentials. On the other hand, the constant availability of learning technology platforms doubles our workload when we are called away to attend to "the business of life" by work commitments, illness, family trauma, or the need for travel or family 
vacations. How do adult learners negotiate with themselves their "time-out" from online learning? How does their time-out affect their perceptions of their learning and the learning domains characterized by social, cognitive, and teaching presence? This paper reports the findings of a participatory action research project in which a small group of adult learners who were engaged in master's level study in a distance education program at a large American university worked together with the researcher to consider the issues underlying the reality of absenting themselves from their learning community and disrupting the regularity of process that they had developed to maintain their learning progress.

\section{The Study}

The qualitative research study that is reported here evolved with a participatory action intention in that the research question arose in conversation among participants, who were the learners, and a curiosity-driven researcher, who was the instructor. To observe the integrity of the learner-teacher relationship, the researcher did not initiate the research project until after the class had ended. Given this timeframe, there was no possibility to enact the findings of the research or to implement any kind of change based on our collective discoveries or wisdom (Wadsworth, 1997). Motivated by the spirit of participatory research, however, the research questions were derived from a collective, shared experience, and a number of data-gathering occasions reflected an iterative and interactive design.

\section{Genesis of the Study}

During the 16-week duration of a master's course offered by distance at an American university, many of the adult learners, who were engaged in rigorous online interactions with course material, the instructor, and their classmates (Moore, 1989), had to leave the course for periods of up to two weeks' duration. These absences arose from typical adult-learner circumstances: parental illness/death, family vacation, work assignments, work-travel assignments. When extensive class dialogue resulted from learners' announcing their impending absences, the instructor took note of the ensuing dynamic and became intrigued as to its impact on the group's learning, specifically in the areas of affective domain, social presence, and community.

\section{Participants}

In a class of 18 learners, fully $50 \%$ of the group took a leave of some sort $(N=9)$. Several learners indicated the need to absent themselves more than once and for different reasons. The reasons presented for extended absences included work demands (4), family pressures/demands, including child and health issues (3), work-related travel (5), and family vacations (3). The six learners who eventually responded to the post-course invitation to participate in a research project on "travel learning" were male and female middle-class adult learners, who were employed fulltime. Geographically, they were located in three countries on two continents. Beyond these facts, no attempt was made to gather more specific socio-economic data. All participants were English speakers. 


\section{Research Questions}

The overarching research question driving this study was the following: "How do learners experience extended absence from their learning communities?" Because of the evolutionary and participatory nature of the research design, the initial issues that would work themselves into subquestions were identified by the study's participants and formed the framework for four rounds of data collection, described below.

\section{Methodology}

Unlike other research projects in which the writer has been involved, this study generated a gentle and iterative knowledge-building type of data gathering. Each round of questioning and exchange expanded on and delved further into the issues. The door was always open for participants and researchers to exchange thoughts, clarify questions, and probe the data. Various combinations of the six participants interacted with the researcher and each other at all times in conversational exchanges. Each round of data gathering is described below.

\section{Round one.}

Data collection began with the distribution by email of this question: "What issues are raised for you when you contemplate an extended absence from an online course?" Participants reflected on this question and responded with various degrees of commentary on their lists of issues. Participants also opened up a Google site for discussion that arose from their responses.

\section{Round two.}

Working from participants' initial responses, the researcher extrapolated nine common issues and approached the participants a second time with this request: "Please reflect on these issues. Do they make sense to you? Do you think this captures the 'deal about having an absence from your regular learning routine"'? Then two more requests were made of participants: 1) "Moving to a next level, think in terms of learning domains (cognitive, affective [social], psycho-motor). Does any one of these domains stand out as the one that is most affected by the actions needed to enable an absence?" and 2) "If you were an online instructor (and some of you are...) and a student came to you to tell you about a proposed fairly lengthy absence from class (how long would that be?), what question(s) would you put to the student to ensure that he/she had everything under control?" Responses from seven participants to these enquiries were returned by email and posted to the Google site. 


\section{Round three.}

From the data received, the researcher refined several seed questions to initiate a real-time online focus group among those participants who could attend. The usual type of circumstances that hinder synchronous conferencing prevented many of the participants from attending the session, which was held by mutual agreement on a Saturday; one participant was travelling and two had family commitments. As a result, only two participants and the researcher chatted online for an hour. The transcript was recorded and sent to the participants for their validation and responses. Concomitantly, the researcher constructed a learning style inventory instrument for distribution by email to all participants and explained that she would use it as a categorizing tool for the study's data. The inventory that was used combined Kolb's (1984) categories of learning styles (AR, AS, CS, and $\mathrm{CR}$, where $\mathrm{A}=$ abstract, $\mathrm{C}=$ concrete, $\mathrm{R}=$ random, and $\mathrm{S}=$ sequential) with Grasha's (1996) similar inventory of styles. Its purpose was to allow participants to self-identify their learning styles in order to provide a categorizing mechanism for analyzing their behaviours when dealing with absence. Four participants completed and returned the inventory.

\section{Round four.}

During the next month, the researcher continued to analyze, categorize, and thematize the data. During this time, she engaged in several one-on-one question-and-answer exchanges with participants as she sought to clarify data. Some discussion evolved within the Google site in response to postings, but the group's energy level was dissipating. A final question went out to participants three months after the initial data gathering. Five participants responded to these questions:

1. Looking back, what aspect of your being away from your online class do you recall causing you the most grief/anxiety? (or substitute another noun here, depending...)

2. As a learner, did you learn anything about yourself and your ability to be a good learner from that episode?

3. Would you feel comfortable taking a lengthy absence again from online study? (Or, have you, since then?)

\section{Limitations of the Study}

There was an obvious limitation to this study that superseded the normal limitations of small, qualitative studies that are not able to be generalized to a larger population. Several more learners from the group were invited to participate in the study from its inception - invited to contribute ideas, questions, and issues - based on the fact that they had also experienced absences from the class. Some of these learners performed less well than others; some of these learners in fact suffered from their absences to the extent that they were not able to maintain an adequate level of commitment to the course and fell by the wayside, either immediately following an absence or a little later on, as it became more difficult for them to attempt to catch up. All told, the participants that engaged in the study were strong and successful learners; repeated efforts to engage some of 
the other learners were not successful. There is, therefore, an element of self-selection here that is recognized by the researcher but deemed unavoidable.

\section{Literature Review and Theoretical Framework}

The complex individual and social nature of online learning has been well researched and documented in recent years. This research draws on two bodies of literature, the most fundamental being the implicit understanding of adult education principles that underpin most discussions of online learning. From the adult education literature come notions of self-direction, autonomy, respect, and independent learning (Brookfield, 1990; Knowles, 1970; Renner, 2005) as well as notions of the value of adults' experiential learning and the role that learning plays in their engagement in occasions of formal learning (Dewey, 1938). Additionally, the study is framed both by Garrison and Anderson's (2003) community of inquiry work and by learning style theory, most notably Kolb (1984). Initiated by Garrison, Anderson, Archer, and Rourke's seminal "presences" research almost a decade ago, constructivist thinkers in the field of distance education have focused on "webs of significance" (Geertz, 1973) that constitute the online learning dynamic. From myriad research studies, our perception of what was once thought to be a technology-enhanced communication has developed into an understanding of a very layered enterprise (Blanton, Moorman, \& Trathen, 1998). To understand and discuss the research findings, this study uses Garrison and Anderson's (2003) community of learning framework and adds to this framework distance education's understanding of the concept of community in learning and among learners and also builds on two notions of learning style. Kolb's (1984) experiential learning model is juxtaposed with Grasha's (1996) online learners' typology and used as a foundational categorization strategy.

Garrison, Anderson, and Archer's (2000) articulation of cognitive, instructional, and social presence gave online theorists and researchers a useful schema through which to conceptualize the complex interaction of online learners' learning processes. From this solid starting point, subsequent and related research has investigated more deeply the various factors that define and connect online learners. Whereas the interrelated nature of the online learning dynamic is recognized by this writer, the nature of this study invited a closer look at cognitive and social presence constructs than at teaching presence, and the analysis of the findings and the subsequent discussion highlight the key roles of learners' sense of cognition and their devotion to maintaining their cognitive presence when absent from their learning group. Interestingly, recent quantitative data on the progression and integration of online social, cognitive, and teaching presence over time (Akyol \& Garrison, 2008) support the predominance of cognitive presence among learners, while at the same time acknowledging the intricate intermeshing of all three presences. Akyol and Garrison's (2008) study, while reporting on changes in the delicate balance of an online course over time, did not raise the issue of learners' prolonged absences from the community dynamic; however, the researchers did recognize the complexity of online learning's "constituting elements and categories" within the "dynamic nature of a community of enquiry" in calling for further investigation into the nature of that community. Coming at the concept of community from its perspective as a substantive factor in the makeup of online learners' affective domain, Conrad's research (2005) demonstrated a robust, vital sense of group cohesiveness that 
responded to many stimuli, including the length of the study period of the course or program, the integration of distance study with face-to-face meetings, and patterns of community evolution over time.

In a quantitative study involving 135 participants, Wang et al. (2008) investigated the psychological characteristics of distance learners to determine the relationship between learners' levels of motivation, their self-efficacy, and their learning results, determining that "learning motivation and learning strategies are clearly associated with positive and predictable effects on learning results" (p. 17). Building on Ausubel's theory of learning motivation, Wang et al. gathered their data from a questionnaire that explored the three dimensions of learners' intrinsic motivation. For the purposes of this study, however, Wang et al.'s (2008) findings were most relevant in their support of Shih and Gamon's (2001) work, which concluded that "the level of learning strategy is one of the most important factors in determining learning results" (p. 25).

Where do learners' learning strategies come from? Motivation theory is one place that provides background against which to think about the connection between online learners' learning success and learning strategies. Raymond Wlodkowski, arguably one of the strongest voices on adult motivation, suggests that the highest level of adult motivation arises when "the adult has experienced learning as pleasurable and intrinsically motivating” (2008, p. 101). Wlodkowski's third edition of Enhancing Adult Motivation to Learn (2008) is valuable to this study because of its detailed attention to the cognitive aspects of adult learning but also because of the author's emphasis on cultural - broadly speaking - inclusiveness and social relevance as important parts of the learner's landscape. Wlodkowski ties motivation-to-learn to "our acute awareness of the degree of our inclusion in a learning environment" (p. 126). Research into online community supports this view (Conrad, 2005; Kehrwald, 2008).

\section{Findings of the Study}

The results of this study confirm the fact that a network of strongly interconnected factors guides learners' decision-making when they are faced with the need to absent themselves from their regular online learning. Working in an adapted participatory style, as described above, the study's first round of data collection asked participants $(N=6)$ to respond to the following question: "What issues are raised for you when you contemplate an extended absence from an online course? What issues do we need to be aware of? Think not only in terms of study and learning areas, but also of the affective domain, and of any other peripheral factors that play into the arrangements or deals that you make with yourself in order to facilitate the absence and/or the learning." Participants' responses to this opening question brought forth many issues, which were placed by the researcher into the following categories (in no particular order): connection with other learners; connection with materials and resources; self-knowledge (learning style, learning needs, learning rhythm); making physical arrangements for technology and for connections with course; dealing with assignments; enhancing classroom learning through travel experiences (e.g., "giving back"); planning or setting priorities; family support or arrangements; and control of environment and of self. 
In the second round of data collection, learners were asked to reflect on these issues and to consider whether they captured the essence of "having an absence from your regular learning routine." They were also asked to "move to a next level" by "think [ing] in terms of learning domains (cognitive, affective (social), psycho-motor)" and noting whether any one of these domains stood out as the one that was the most affected by the actions needed to enable an absence. Finally, participants were asked this question: "If you were an online instructor, and a student came to you to tell you about a proposed fairly lengthy absence from class (how long would that be?), what question(s) would you put to the student to ensure that he/she had everything under control?"

Participants unanimously agreed that the issues extracted from the first round of data-gathering were indeed the salient ones. The second question generated responses that identified both the cognitive and affective domains as being impacted by absences, although most learners clearly indicated that the cognitive domain was of foremost importance to them. The most revealing outcome from this question was learners' connection of the cognitive domain to the affective domain, expressed in statements like this one: "I personally depend on other classmates to stimulate my thinking process." This finding supports research confirming not only significant relationships between cognitive presence and satisfaction and between cognitive presence and perceived learning but also that "social presence through group cohesion ... supports integration and higher levels of cognitive presence (e.g., integration)" (Akyol \& Garrison, 2008).

The third question asked learners to respond from a hypothetical or real instructional perspective. Only one participant had experience as an online instructor (although all had face-to-face instructional experience); that participant contributed two anecdotes to illustrate her responses. That said, all participants' responses, both theoretical and real, emphasized their concern that logistical arrangements should be well-confirmed for learners before embarking on a lengthy absence from the online experience. The following are some of the questions that they would ask of students:

- When will your assignments be submitted?

- Will you have access to a computer?

- Will you have Internet access?

- Which resources will you count on to help you stay on track?

- How do you plan to overcome any obstacles that you may face during your absence?

- Are you aware of the course syllabus?

Participants also indicated that in an instructional role they would give the following advice to students who were preparing for a lengthy absence:

- You must prepare for your absence by setting up a web-based repository for necessary documentation.

- Be sure to take the right resources. Don't get caught with the wrong readings or books!

- Look carefully at assignment due dates.

- Let your instructor and classmates know that you will be gone. 
- If you're involved in small group or collaborative work, let those classmates know up front that you will be absent or less available than usual.

Round three's data came from an hour-long online chat among two participants and the researcher. The exchange was recorded by a software program and a transcript was produced. Several of the same themes as had arisen in previous exchanges were reiterated, although in a more casual fashion given the conversational flavour of the chat function. The learners involved were also quite familiar with each other from repeated course contact. Themes that were repeated from prior data are outlined below:

- Absenting oneself from an online course required conscientious and diligent planning, which included the following: knowing when and where you would be driving or flying, so as to arrange work-time; knowing whether or not the destination would have reliable Internet access, wireless, or printers; and ensuring that the correct materials were packed, including course readings or textbooks. Such planning also included the choice of whether or not to enrol in a course when vacation or travel was looming on the horizon.

- Some absences may be more easily accommodated than others (due to location, type, length, etc.).

- Individuals who are not by nature "planners" needed to become planners in order to succeed in their absence.

- Regular routines had to be adapted in order to fit course work into absences.

- Assignment due dates were "red-letter" factors in planning absences.

- There was a perceived difference in importance between assignments and participation in discussions.

- It was considered important to have access to the course's syllabus well ahead of time and to know with confidence that the syllabus would not change.

- There was an expectation that instructors' demands would be flexible as well as a recognition that such flexibility was the norm in cases of emergencies, such as a death in the family or power outage due to a severe storm.

- Chatting with classmates maintained the level of connection and the feeling of connectedness.

Interestingly, two new themes emerged from this informal exchange. (The chat occurred on a Saturday, which also may have been a factor in the level of informality.) Firstly, anxiety levels rose according to the complexity of the travel plan and the number of logistical issues involved (e.g., whether or not there would be a reliable Internet connection in a hotel in another country). And secondly, these participants felt that some students would "always have excuses for not being [online]." One participant commented that as adults we suppose that we can manage our time and coordinate our activities so as to be able to fulfill the obligations of the course. The other, acknowledging that he had himself figured out how to do this, agreed: "There seem to be several folks who used travel as an excuse not to be there...because I've figured out how to do both, I wasn't overly sympathetic." Both participants couched their remarks by acknowledging that there were many extenuating factors at play in these types of situations. 
Round four's data collection asked learners to look back on their experience and to reflect after a four-month passage of time. Julia was clear and decisive in her reflection: "I had been 'absent' in a prior course and that experience made me unwilling to be absent again." Similarly, Don was not comfortable with the thought of another extended absence. He reflected on his current learning experience, comparing it with the course under study:

Right now I'm taking the capstone course. Next weekend I am going on a trip and don't expect to be able to check in at all; however, the capstone course is not set up for debates, discussions, etc. It is mostly work on your own - project and portfolio. So I don't think I'll feel like I'm missing out! At least, I hope not.

Hannah reflected that while three or four days might be alright, an absence of more than a week would be too disruptive for her. Carol came away with the exact opposite type of experience. Knowing that she had succeeded through her organizational measures to be successful in spite of a lengthy absence, she felt she could manage such an absence again. (No contrast is intended between Julia and Carol as students. Both were very successful learners.) For Carol, though, having experienced high anxiety around the question of whether or not she would be able to find convenient Internet access, knowing that she would be able to cope left her feeling completely at ease.

\section{Discussion}

As described above, the impetus for this study arose out of online class members' efforts to situate themselves properly - according to their perceptions - when they were going to be absent from the group for a long period of time. In most cases, this was about two weeks, constituting over a 15 week course approximately $13 \%$ of the length of the course. Translated to a traditional face-to-face 39-hour course, this length of absence equates to missing 5 hours of class time, or approximately two three-hour lectures. Absences expressed in those terms do not seem to be such a big deal! How many of us, in our own years of studentship, simply did not show up for lectures?

But there is a difference that cannot be interpreted quantitatively by comparing these numbers, and the difference lies in the now-understood notion "that meaningful and worthwhile learning is associated with collaborative communities of inquiry" (Akyol \& Garrison, 2008). This is true of online learning for several reasons: the connective heart of a learning community must exist in a distributed manner; online learning succeeds best using constructivist approaches that both foster and require collaborative input; and the asynchronous generation of knowledge on discussion boards is fluid and multi-faceted. At a practical level, online courses usually feature a participation grade that is awarded based not on quantitative measures but on a representative spread of participative activities by the learner throughout the course. Sustained absence from the course could potentially threaten participation grades. But a more severe and potentially disruptive result of sustained absence concerns learners' separation from other learners and from the sense of community that hallmarks Wlodkowski's (2008) desired state of inclusivity. For 
many learners (not all) engaged in constructivist learning environments, the binding-together and sharing of common purpose serves as a powerful learning device.

This study's participants all labelled themselves as "cooperative" learners on Grasha's (1996) scale. From among several choices, such as competitive (wants to be first), avoidant (nonparticipating), participant (eager to accomplish), dependent (looks to instructor for guidance), independent (thinks for self, likes to work alone), they chose the option "collaborative, shares ideas and information." The course's archival records support participants' self-selection in this regard. Interestingly, whereas round three participants who completed the learning styles inventory $(n=4)$ unanimously declared themselves as collaborative learners, they differed in their labelling of themselves on Kolb's scale. From this, the researcher surmised that they had thought carefully about their choices and that the task of self-categorization did not lend itself to an automatic pairing of categories. Ultimately, therefore, while the results of participants' selfcategorization confirms that they are indeed willing, constructive, and collaborative-minded learners, the results also reaffirm the limitation of the study: this handful of online learners who shared their concerns and insights about the nature of their online absences were already committed online learners, who both understood and had made their peace with what was being asked of them in an online course.

This study's findings break down into three major themes: the validation of the interconnectedness of cognitive, social, and instructional presence (Garrison \& Akyol, 2008); the importance of learners' self-knowledge, comparable to Wang et al.'s (2008) understanding of meta-learning; and the always-relevant impact of external and circumstantial life-situations on adult learners' ability to engage in learning. None of these themes can be distinctly separated from the other. In that sense, the Venn diagram used by Garrison and Anderson (2003) to capture the interrelated nature of the three presences could be used conceptually here to represent the meshed nature of all the learning factors named above; that is, the three presences would be set among and complemented by both internal and external factors contributing to learners' performances.

\section{Validation of the Interconnectedness of Cognitive, Social, and Instructional Presence}

The study's data spoke clearly to the fact that learners valued most strongly their ability to maintain a strong cognitive presence during their absences from online classes. One respondent described at length her decision-making process, which centred on assignment due dates in relation to the dates of a planned family vacation:

I knew that traveling with my [children] would mean that I would have zero "metime" let alone a chunk of time to research and write an assignment. My preferred way of writing assignments is to give myself at least two full days with no interruptions where I can work alone for at least 7 consecutive hours. I hate having to write assignments in small bits of time. It makes me feel really stressed and discombobulated. 
This student asked the instructor if she should withdraw from the course but was reassured that arrangements could be made to resolve the situation satisfactorily.

Don had been in the process of changing jobs and relocating during the course, and he commented that he was sorry to be away:

...there were good things going on there... discussion and/or debate... that I was missing. I like to get into the thick of things in my courses and check in a few times every day, so not being able to get internet access was frustrating. When I returned from my trips, I had to read through several days of postings in one sitting. Not only was it time-consuming, it was difficult to determine the sequence of the action: generally there are several conversations going on, and classmates tend to reference other ongoing discussions in other threads. If you are not reading them in real time, it's hard to recreate the flow.

Don was also aware that the finer logistics of timing contributed to the quality of interaction that permits constructive knowledge-building online. He described his attempts to catch up toward the end of a discussion forum: "Often, no one responds to a late post and it just hangs out there in space; they may not even be reading the late posts because they have already moved on."

Similarly, Hannah connected timing issues to her own cognitive functioning in the course, functions that she found were disrupted by her absence: "I wasn't able to ask questions of the other students and I was often a couple of days behind in reading the posts. By the time I could comment, the other students had moved on to the next issue."

When asked pointedly which domain they felt was most affected by absence, all participants indicated the cognitive domain. They also, however, appended to that statement subsequent statements explaining the ways that they felt that their activities in the cognitive domain slipped over into activities in the affective domain: "So, did my 10-day vacation have an impact on my online experience as I had sorted out the assignment problem? Yes. I hadn't reckoned on how much online learning depended on active participation in the conferences."

Other participants commented on the connection that existed for them between the quality of their learning and the interaction they experienced - and missed out on, when away - with their colleagues.

I personally depend on other classmates to stimulate my thinking process. I read and form an opinion or understanding and then compare what others have to say to my own thoughts. Sometimes I change my mind based on the arguments of others. The interaction helps me to reanalyze my position which enhances my learning process.

Not being able to check in when I wanted to did make me realize that I am a very social learner. I like to be where the action is, and being isolated from it was 
tough for me. I think that it challenged my ability to be a good learner. I learn by doing.... by reading and participating... and I felt as if I was not learning during the times I was away, even though I was reading articles or doing other work for my class.

Learners' perceptions of the interconnection of their own learning progress to the comfortable and collaborative learning milieu engendered by the presence of online colleagues indicated that they have realized a level of harmony and integration that has been upheld by educators and researchers as attrition-reducing and support-engendering (Conrad, 2005; Kehrwald, 2008; Moore \& Kearsley, 2005; Tinto, 1993). Accepting then that the sense of belonging, well-being, and connection that Garrison and Anderson (2003) depict as the overlapped centre in the "presences" model was understood and valued by these learners, the question arises: what strategies or factors are at work as they attempt to retain the necessary harmony when they prepare for a lengthy absence from the group's dynamic? This study's data, supported by the literature, maintain that both instructional presence and learners' own self-knowledge are important factors.

Participants indicated that the actions and attitudes of instructors were critically important in making absences possible. Carol became aware of her organizational capabilities after a lengthy absence traveling in Europe but credited her instructors with helping to make her absence palatable. As she contemplated another absence from the two online courses that she was enrolled in, she offered this comment:

Both my online instructors have already posted all the activities for the course. This gives me the opportunity to plan my readings in advance and organize my time while away from class. I already know what I have to do and how I have to do it, which gives me confidence during my absence.

In this sense, although the primary foci of learners' concerns could be labelled as cognitive and social, the impact of instructional presence was also important to absentee learners. They needed to be able to depend on supportive instructors with whom they could negotiate the terms of their absence. Additionally, learners needed to be able to count on dates and assignments remaining stable so that they could plan informed absences.

\section{Learners' Self Knowledge}

Contained within this category are two elements, maturity and learning styles. By learning styles, I refer to learning habits rather than to inventory-designed preferences, such as Kolb's abstract sequential (AS) or Grasha's "competitive" learning style. Rather, the example outlined previously that documented a learner's struggle to arrange her schedule to match her course's assignment due dates is an example of a learning habit: this learner is in the habit of checking assignment due dates and, in the case of upcoming travel, ensuring that the dates are feasible for her. This learner's demonstrated intrinsic motivational strategies also confirmed previous studies' data that highlighted the importance of learners' level of learning strategies (Shih \& Gamon, 2001; Wang et al., 2008). 
That same learner also realized that the "lurker" style of learning was not for her. Reading other learners' posts after-the-fact "did not really help me in the usual way that reading other students' postings do." Switching over to cognitively-based observations on her own style, she continued:

Usually when I read postings, I'm reading actively, i.e., as I read, I'm measuring up that response with what I have/will post on the same topic. I'm thinking about what I'm going to reply, what I'll say, do I need to go away and ponder this point? However, reading closed conferences [upon her return] in which I could not participate, I found that I read passively, counting how many posts I had to read and plodding through them without really interacting with the content in the usual way.

Learners expressed their individual nuggets of self-knowledge in various ways. One wrote, "For me, taking an online course means that I commit to being around a computer for the whole course. Another wrote, explaining the necessity for careful choices of what materials to take away with her while traveling, "I don't like to read on the screen so having the documents with me worked better."

Carol, a self-described organized learner, also commented that becoming a "witness learner" while away helped to reduce her anxiety level as she "kept informed about what was happening in my class during my absence." Carol also reported that her two week absence from class reinforced her own sense of being responsible and organized. "I had time to plan my trip and I made sure I took all my readings with me so I could read them while being at the airport, in the plane or even at nights." Carol organized her holiday time so that she could spend time with her family and enjoy her trip "while having my readings and assignments [done] on time."

Some learners revealed self-knowledge concerning the impact of timing and immediacy on the quality of their responses. The issue of immediacy is telling given that asynchronous learning, as in the course under study, is criticized by some for not offering learners a sense of immediacy. For Don, regular attendance during the course allowed him to feel involved and to contribute what he felt was meaningful and "honest." However, he added:

When you get there after the fact [after an absence], you really cannot naturally enter the conversation and add your thoughts and comments. It ends up being more artificial and more of an afterthought and your peers generally have already moved on to other topics and discussions.

The thoughtful reflections of learners on the nature of their own learning are indicative of levels of maturity and emotional intelligence. Research indicates that mature learners are better equipped for success in online learning (Berenson, Boyles, \& Weaver, 2008). Wlodkowski, referencing Goleman's seminal research on emotional intelligence, suggests that "intellectual capacity during adulthood is a combination of genetic expression, experience, and knowledge that displays continued growth and highest potential in culturally relevant, real-life situations" (2008, 
p. 41). Learners in this study clearly demonstrated the coalescence of these maturity-related factors while they constructed academic success amidst real-life situations that had the potential to affect their studies.

\section{Impact of External Factors on Adult Learners' Ability to Manage their Learning}

Traditional learners have always cited personal issues as a major reason for dropping out of courses (Moore et al., 2002; Wiesenberg, 2001). The notion of personal issues contains a cluster of factors: time, money, work, personality conflicts with others, and so on. Similarly, online learners cite personal issues as contributing to their inability to complete online study, but in addition online learners cite issues of "support" as critical to their success (Moore \& Kearsley, 2005; Moore et al., 2002; Zembylas, 2008). Augmenting any learner's need for support is the odd circumstance in which many online learners find themselves when they miscalculate the amount of time and challenge that online learning will demand of them (Stanford-Bowers, 2008).

The most carefully arranged study plans can be severely disrupted when online learners - for whatever reason - have to suddenly absent themselves from their routine and their commitment to their learning group. One learner made a clear distinction between her "regular" online load resulting from "just taking online courses in general" and "catching up on missed online work" resulting from an absence: "My husband takes on a lot more childcare duties when I am trying to catch up on work and I rely on him to 'free-me-up' on weekends so I can study." In the same vein, another female learner relied on her husband to "cut his work days shorter so that he could drop off and pick up our son at daycare and shuttle him to soccer practice and games." This family arranged and re-arranged their schedules and childcare routine for the learner's absence. She returned the favour when she returned to allow him "to catch up at work," and then her husband stepped to the plate again on a Saturday to allow the learner "a chance to catch up on a paper." "Logistics!" she commented.

\section{Conclusion}

Online instructors and administrators often need to explain to novice learners the meaning of flexibility as regards online learning. Too often, it is interpreted by learners as meaning, "Do your learning however and whenever it suits you." And although most online courses - with their deadlines and their due dates and fairly routine parameters - still permit more flexibility than traditional place-bound courses, absenting oneself from an online learning experience can take its toll on learners. The adult learners in this study were all strong learners who shared through four rounds of data collection their questions, insights, and reflections on how being absent from their online class for an extended amount of time affected their studentship. As committed and mature learners, they recognized that undertaking absences from their online studies during course-time would require planning and levels of decision-making that recognized the dynamic interplay of cognitive, instructional, and social presences on their learning. Although learners in this study were aware of and attentive to all three domains of learning, their cognitive presence - and the 
perceived need to maintain cognitive success while absent - proved to be the most important factor in their planning process. Learners also recognized the relationship between their cognitive success and both the social fabric of their online course, which supported them in a comfortable learning environment, and the nature of instructional presence that rendered their absence either easier or more difficult. Learners demonstrated a keen degree of self-knowledge, especially as regards their own learning patterns, and were also aware of their interrelationship with and dependence on external factors, such as family support. By melding responsibility with flexibility, this study's learners successfully negotiated additional degrees of "distance" into their distance learning. 


\section{References}

Akyol, Z., \& Garrison, D. R. (2008). The development of a community of inquiry over time in an online course: Understanding the progression and integration of social, cognitive and teaching presence. Journal of Asynchronous Learning Networks (JALN), 12(3).

Berenson, R., Boyles, G., \& Weaver, A. (2008). Emotional intelligence as a predictor for success in online learning. International Review of Research in Open and Distance Learning, 9(2). Retrieved on October 10, 2008, from http://www.irrodl.org/index.php/irrodl/article/view/385/1049.

Blanton, W. E., Moorman, G., \& Trathen, W. (1998). Telecommunications and teacher education: A social constructivist review. Review of Research in Education, 23, 235-275.

Brookfield, S. D. (1990). The skillful teacher. San Francisco: Jossey-Bass.

Cigognini, M. E., Pettenati, M. C., Paolette, G., \& Edirisingha, P. (2008). Guiding learners to become knowledgeable learners 2.0. Proceedings of EDEN Conference 2008, Portugal. Retrieved November 23, 2008, from http://www.edenonline.org/papers/publications/proceedings/Lisbon 08/papers/A2/199.html

Conrad, D. (2005). Building and maintaining community in cohort-based online learning. Journal of Distance Education, 20(1), 1-21.

Dewey, J. (1938). Experience and education. New York, NY: Macmillan.

Garrison, D. R., \& Anderson, T. (2003) E-learning in the 21 st century: A framework for research and practice. London: Routledge/Falmer.

Garrison, D. R., Anderson, T, \& Archer, W. (2000). Critical inquiry in a text-based environment: Computer conferencing in higher education. The Internet and Higher Education, 2(2/3), 87-105.

Geertz, C. (1973). Interpretation of cultures. New York, NY: Basic Books.

Grasha, A. F. (1996). Teaching with style. Pittsburgh, PA: Alliance.

Kehrwald, B. (2008). Understanding social presence in text-based online environments. Distance Education, 1(29), 89-102.

Knowles, M. (1970). The modern practice of adult education. Chicago, Ill: Follett.

Kolb, D. A. (1984). Experiential learning: Experience as the source of learning and development. 
Englewood Cliffs, NJ: Prentice-Hall.

Moore, M. G., \& Kearsley, G. (2005). Distance education: A systems view (2nd ed.). Belmont, CA: Thomas Wadsworth.

Moore, K., Bartkovich, J., Fetzner, M., \& Ison, S. (2003). Success in cyberspace: Student retention in online courses. Journal of Applied Research in the Community College, 10(2), 107-118.

Müller, T. (2008). Persistence of women in online degree-completion programs. International Review of Research in Open and Distance Learning, 9(2). Retrieved on September 21, 2008, from http://www.irrodl.org/index.php/irrodl/article/view/455/1042

Renner, P. (2005). The art of teaching adults: How to become an exceptional instructor and facilitator. Vancouver: Training Associates.

Rourke, L., Anderson, T., Garrison, D. R., \& Archer, W. (1999). Assessing social presence in asynchronized text-based computer conferencing. Journal of Distance Education, 14(2), 50-71.

Shih, C.- C., \& Gamon, J. (2001). Web-based learning: Relationships among student motivation, attitude, learning styles, and achievement. Journal of Agricultural Education, 42(4), 12 20 .

Stanford-Bowers, D. (2008). Persistence in online classes: A study of perceptions among community college stakeholders. Journal of Online Learning and Teaching, 4(1), 37-50.

Swan, K., \& Shih, L. (2005). On the nature and development of social presence in online course discussions. Journal of Asynchronous Learning Networks, 9(3). Available at http://www.sloan-c.org/publications/jalm/v9n3/v9n3_swan.asp

Tinto, V. (1993). Leaving college: Rethinking the causes and cures of student attrition (2nd ed.). Chicago: The University of Chicago Press.

Wadsworth, Y. (1997). Do it yourself social research (2nd ed.). Sydney, Australia: Allen \& Unwin.

Wang, Y., Peng, H., Huang, R., Hou, Y., \& Wang, J. (2008). Characteristics of distance learners: Research on relationships of learning motivation, learning strategy, self-efficacy, attribution and learning results. Open Learning, 23(1), 17-28.

Wiesenberg, F. (2001). The roller coaster life of the online learner: How distance educators can help students cope. Canadian Journal of University Continuing Education, 2(27), 33-59. 
Wlodkowski, R. (2008). Enhancing adult motivation to learn: A comprehensive guide for teaching all adults (3rd ed.). San Francisco: Jossey-Bass.

Zembylas, M. (2008). Adult learners' emotions in online learning. Distance Education, 1(29), 71-87. 